\title{
Nurses' Perception Job Violence and It Is Relation to Their Absenteeism
}

\author{
Warda Hussein Mohammed ${ }^{1}$; Sanaa Mohamed Araf ${ }^{2}$; Amira Mostafa Fahmy ${ }^{3}$
}

1. B.Sc. Nursing

2. Assist. Professor of Nursing Administration, Faculty of Nursing, Minia University.

3. Lecturer of Nursing Administration, Faculty of Nursing, Minia University

\begin{abstract}
Background: Workplace violence toward nurses has increased, with severe consequences to professionals and their healthcare organizations. Violence towards nurses may have long-term consequences not only on nurses' personal lives and their ability to care for patients. Aim: To assess nurses' perception of workplace violence, and it's relation to their absenteeism. Research design: A descriptive correlational research design. Subjects: A convenience sample of staff nurses working in Elfkrea Hospital $(\mathrm{N}=180)$. Setting: Elfkrea Hospital, Minia governorate, Egypt. Tools of data collection: included two tools; first tool Workplace violence Questionnaire; second Absenteeism Questionnaire. Results: the majority of staff nurses have been exposed to workplace violence, and minority of them have not been exposed to workplace violence. More than half of staff nurses have been instructed to report physical or verbal abuse regardless of the severity or harm to the direct manager and security. Most of the patients relative the main responsible for it followed by more than two-thirds of them were patients themselves, and the minority were the physician and charge staff nurses and more than three-quarters of the staff nurses said workplace violence can lead to absenteeism and more than half of them are sure that workplace violence can lead to retirement. Conclusion: The findings of this study revealed that positive weak correlation between workplace violence among the studied staff nurses and their absenteeism. Recommendations: Policies and legislation targeting violent acts should be instituted and developed, and a high percentage of staff nurses need training in violence management.
\end{abstract}

Keywords: Absenteeism, Job violence, Nurses' perception, Relation

\section{Introduction}

Workplace violence (WPV) is ranked as one of the leading causes of occupational injury in the United States and is common in health settings. Nurses have the highest rate of violent victimization reported in the U.S., thus presenting a significant issue for healthcare leaders. Various researchers focus on prevalence rates of WPV among nurses discussing types of violence, location, and the setting where the WPV occurred. Less information exists regarding the time taken off work and factors associated with WPV among nurses versus nursing assistants (NAs) (Norris, 2018).

Workplace violence toward nurses has increased, with severe consequences to professionals and their healthcare organizations. Between 2002 and 2013, WPV occurred approximately four times more than in the private sector (Occupational Safety and Health Administration [OSHA], 2015). Park et al., (2015) found that $71 \%$ of surveyed nurses had been exposed to some form of violence in the previous 12 months.

Workplace violence can be physical or non-physical. Physical forms of violence include pushing, kicking, and slapping; however, non-physical forms of violence, such as verbal abuse, were reported as the most common forms of aggression. This is more prevalent than physical violence, threats, sexual harassment, abuse, or bullying. Also, there are various ways to categorize the types of violence in the workplace. Usually, the types of violence are defined by multiple behaviors or categorized by aggressor characteristics. Violence could be verbal, physical, or psychological, or include sexual abuse, harassment, bullying, threatening behavior, or aggression that might happen intentionally or unintentionally (Cheung \& Yip, 2017).

WPV can result in nurses experiencing fear, frustration, lack of trust in hospital administrators, and decreased job satisfaction. Furthermore, nurses may become

$P$ a g e $\mid 46$ disenchanted with the nursing profession. As a result, healthcare organizations can be affected directly due to lost workdays and the cost of injuries; these contribute to a shortage of nurses that threatens patient care, increases legal liabilities, and escalates workers' compensation claims (Gillespie et al., 2017).

Costs associated with WPV have significant implications for the health of the workforce and the organization. OSHA, (2016) identified the following areas with significant cost implications for healthcare organizations: increased nurses turnover, recruitment, and retention costs; increased absenteeism from work; reduced efficiency and performance at work; decreased nurses morale; and reduced inexperienced nurses. OSHA also indicated that hospitals incur expenses related to employee and patient injuries, property damage, reduced productivity, increased absenteeism, litigation, decreased employee satisfaction, and workers' compensation.

\section{Significance of the Study}

This study is both timely and important. The most recent research in the healthcare field showed that violence towards nurses in hospitals increases (Itzhaki et al., 2015) and has individual and system effects. The serious individual effect can change a nurse from a healthcare provider to a healthcare patient (Rosen, 2013). The system effect is significant due to the impact on the nursing workforce. Violence towards nurses may have long-term consequences not only on nurses' personal lives and their ability to care for patients (Hutchinson et al., 2013; Pich et al., 2011).

Granstra , (2015) study found that violence between hospital staff is a growing problem, with more than $50 \%$ of nurses experiencing horizontal violence. A recent survey by Purpora and Blegen, (2015) found that horizontal violence 
was higher among nurses with lower job satisfaction and less supportive peer relationships.

A recent report from Queens and Health, (2016) indicated a significant increase in the reporting of occupational violence incidences and stated that in 2014-2015, about 3325 of 5030 reported incidents were from the nursing profession. "Interestingly, the number of reported incidents in the first three-quarters of 2015-2016 has increased significantly. If the trend continues, the projected number of incidents for the 2015-2016 year would be around 6700, an increase of over 30 percent on the previous year. The reasons for this significant increase in the reporting of incidents requires further analysis."

Zhang et al., (2017) conducted an extensive study including 4,125 nurses randomly selected from 28 hospitals in China from seven geographical regions reported that verbal abuse was most commonly experienced at (61.25\%), followed by threats $(36.75 \%)$, physical violence $(25.90 \%)$, and sexual harassment $(2.76 \%)$

Reducing workplace violence can improve the quality of life for nurses in their work environment, the healthcare they provide, and overall patient wellbeing. In addition, a decrease in violence towards nurses most likely will improve nurse retention rates. The under-reporting of incidents of WPV is not uncommon in the healthcare profession. It appears that no research on WPV towards nurses has been undertaken in Egypt in the healthcare setting in the last decade.

There were no previous studies which linked those two interrelated variables together, but Abdel-Salam, (2014) studied Violence against physicians working in emergency departments in Assiut, Egypt, the study results revealed the majority of the respondents $(78.2 \%)$ reported exposure to violence during the previous year: $78.6 \%$ verbal and $21.4 \%$ physical. Moreover El-Houfey et al., (2015) studied Workplace bullying against medical and nursing team working at emergency departments in Assiut University Hospital, the study results revealed, that $93.2 \%, 87.5 \%$ of the nursing and medical team, respectively, were exposed to even one incident of bullying in the previous six months.

\section{Aim of the Study}

The aim of the current study is to assess nurses' perception of workplace violence, and it's relation to their absenteeism.

\section{Research Questions:}

What is the nurses' perception toward workplace violence?

Are there a relation between nurses' perception toward workplace violence and their absenteeism?

\section{Subjects and Method \\ Research Design:}

A descriptive correlational research design was used to achieve the aim of the current study.

\section{Setting:}

The study was conducted at Elfkrea Hospital. This hospital consists of 4 buildings; each building consists of 3 floors. The number of departments is 12 departments, and the number of beds is 24 beds. The number of outpatient clinics is 14 (internal medicine - family planning - ophthalmology nose and ear - tracts - chest - surgery - children - orthopedics dentistry - physical therapy - serology clinic - dermatology - psychological and neurological). One nurse provides nursing care, except for the family planning clinic, which has two nurses. The outpatient clinics work 6 hours a day from 8 am $2 \mathrm{pm}$. The number of nursing staff in the hospital is 180 nurses.

\section{Subject:}

The subjects of the study sample included all convenience nursing working in Elfkrea Hospital, as illustrated in the following table

\begin{tabular}{|l|c|}
\hline Department & No. of nurses \\
\hline Medical & 7 \\
\hline Pediatric & 15 \\
\hline Surgical & 8 \\
\hline Neonatal intensive care unit & 25 \\
\hline Obstetric & 8 \\
\hline Operating room & 8 \\
\hline Intensive care unit & 15 \\
\hline Emergency & 14 \\
\hline Dialysis & 24 \\
\hline Central sterilization & 8 \\
\hline Fever & 10 \\
\hline Isolation & 10 \\
\hline Outpatient clinics & 28 \\
\hline \multicolumn{1}{|c|}{ Total } & 180 \\
\hline
\end{tabular}

\section{Data Collection Tools:}

Data was collected through the utilization of two tools by self-administered questionnaire as follows:

Tool (1): Workplace violence Questionnaire: It was included two parts:

\section{Part I: personal data}

It was used to collect data about nurses. It included eight (8) items related to age, gender, residence, marital status, nursing qualification, current position, years of experience, and attend training in preventing WPV.

\section{Part II: Workplace violence Questionnaire:}

This tool was developed by the Emergency Nurses Associations (Emergency Nurses Association, 2010) and translated into Arabic by the researcher to assess the perception, education received, and the reporting behavior related to workplace violence.

\section{Scoring system}

It consisted of 11 items with three Likert scales ranged as not at all safe $=1$, to some extent safe $=2$, and extremely safe $=3$, multiple-choice, yes or no, and openended items.

\section{Tool (2) Absenteeism Questionnaire:}

This tool was developed by the researcher and translated into Arabic to assess nurses' absence from the workplace and different organizational stimuli that contribute to a nurse's effective performance. It consisted of 5 items

\section{Scoring system}

The scoring system was range from 0 to 17 . Higher scores indicate a greater level of absenteeism, while lower scores indicate less level of absenteeism. 


\section{Validity and Reliability of Tools:}

Tools were tested for content validity by a jury of (5) experts in the field of Nursing Administration, and necessary modifications were done.

Each expert panel was asked to examine the instruments for content coverage, clarity, wording, length, format, and overall appearance. No necessary modification was done from the jury panel.

Reliability of the tools was performed to confirm the consistency of the tool. The internal consistency was measured to identify the extent to which the items of the tools measured the same concept and correlate with each other by Cronbach's alpha test that revealed good internal reliability for the tools as $0.830 \& 0.767$, respectively.

\section{Pilot Study}

Before starting of data collection a pilot study done on ( $10 \%$ of the total subjects) (18 nurses), this pilot study aims to test the tool's clarity, comprehensiveness, and applicability and estimate the appropriate time required to fill the questionnaire.

\section{Ethical Considerations}

Before the conduction of the pilot study and the actual study, official permission and consent were obtained from the Dean of the Faculty of Nursing, the Ethical Committee in the Faculty of Nursing, and the Director of Minia General Hospital. Consent was obtained from staff nurses willing to participate in the study after explaining the aim. Study subject have the right to refuse to participate and withdraw from the study without any rationale. Study subject privacy is considered during the collection of data. Staff nurses were assured that all their data were highly confidential; anonymity was also assured by assigning a number for each nurse instead of names to protect their privacy.

\section{Data Collection Procedures:}

Official letters to obtain the approval were introduced to Faculty Dean; this letter included a brief explanation of the study's objectives. Written approvals were obtained from the Director of Elfkrea Hospital and head of departments of the Elfkrea Hospital after explaining the purpose of the study.

Tools were adopted and translated into Arabic; then collect the jury approval for the tools to collect data of the study. The tools were distributed to all the staff nurses after explaining the purpose and process of data collection. Tools were directly administered and supervised by the researcher with the assistance of the head nurse for each department.

The researcher interviewed staff nurses through the morning shift during the working days and distributed the tools. Staff nurses were given 10 to 20 minutes to answer all the tools. They were allowed to discuss with the researcher any item that needed more clarification. The data collection was performed from head nurses and all health insurance hospital staff nurses for six months from the six months from the middle of March to the middle of December 2019.

\section{Statistical analysis of data:}

Data entry was done using a compatible personal computer. And the content of each tool was analyzed, categorized, and then coded. After data were collected, it was revised, coded, and fed to statistical software (SPSS) version 20. The given graphs were constructed using Microsoft Excel software.

\section{Results}

Table (1): distribution of staff nurses personal data (no.=180)

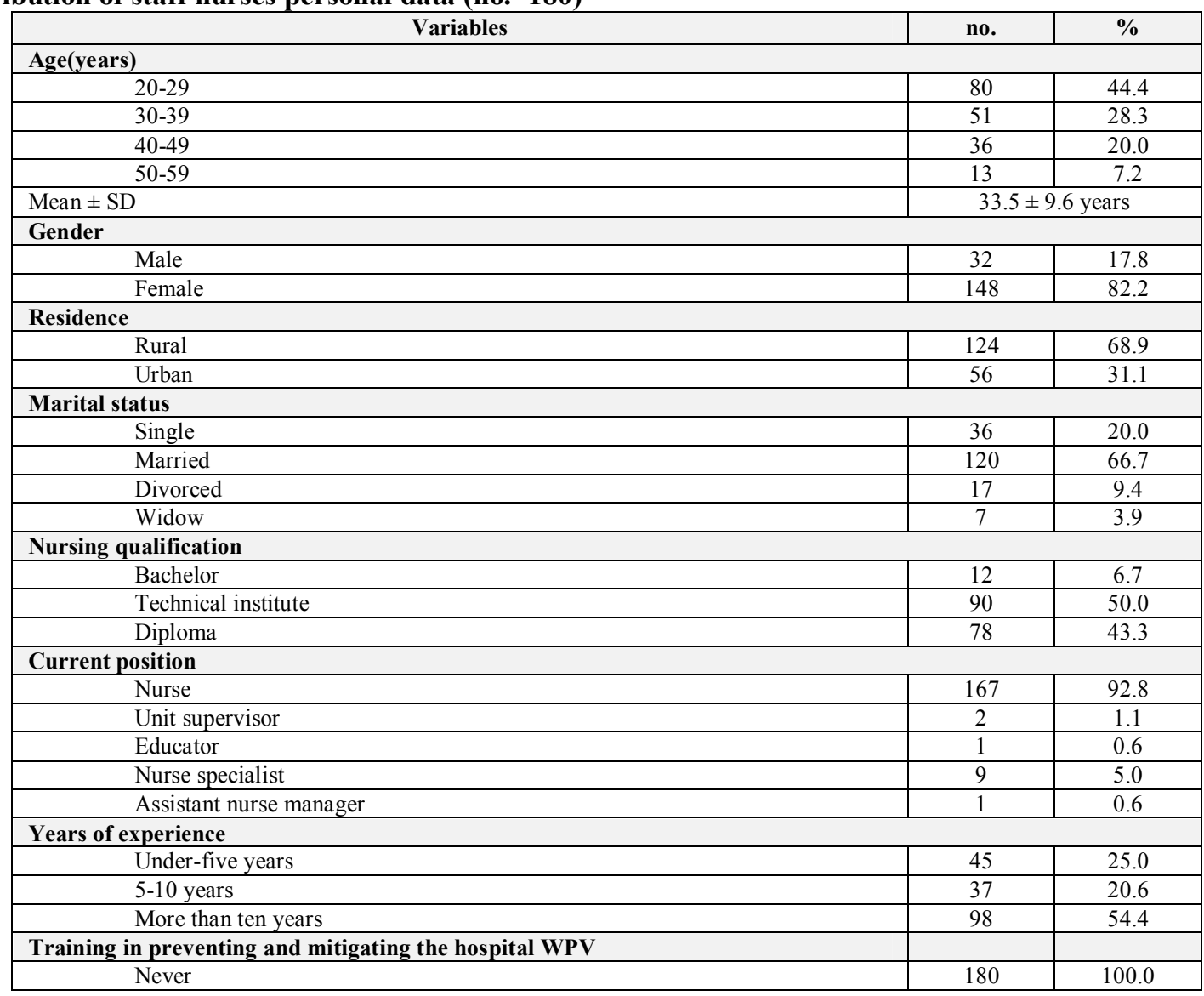


Table (1) shows that nearly to half (44.4\%) of staff nurses are in the age group 20-29 and nearly to third (28.3\%) in the age group 30-39. Also, the majority (82.2\%) of staff nurses are females. More than two-thirds $(68.9 \%)$ live in a rural area, and $66.7 \%$ are married. The nursing qualification of half of the staff nurses are Technical institute while 43.3\% have Diploma. The majority (92.8\%) are staff nurses while $5 \%$ are nurse specialist. More than half $(54.4 \%)$ of staff nurses have $>10$ years of experience while a quarter $(25 \%)$ have $<5$ years of experience, and all (100.0\%) of the studied staff nurses have never received training in preventing and mitigating the hospital WPV.

\section{EXPOSURE TO WORK PLACE VIOLENCE}

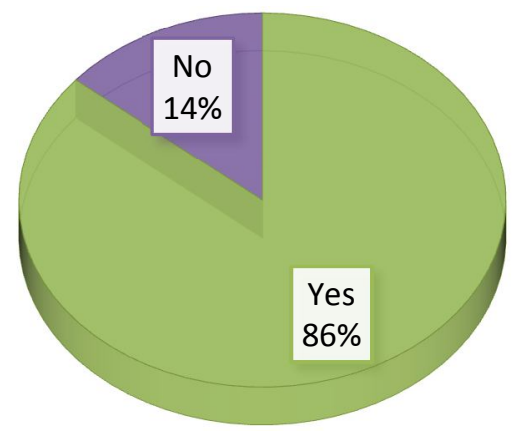

Figure (1): Percentage distribution regarding exposure to workplace violence among staff nurses (no. $=180$ )

Fig. (1): shows that the majority $(86.1 \%)$ of staff nurses have been exposed to WPV, and $13.9 \%$ of them have not been exposed to workplace violence.

Table (2) distribution regarding suggestions of the studied staff nurses for workplace violence handling (no.=180)

\begin{tabular}{|c|c|c|}
\hline \# Suggestions & no. & $\%$ \\
\hline Availability of enough security personnel in each department & 161 & 89.4 \\
\hline Informing the patient of his rights and duties & 16 & 8.9 \\
\hline Putting laws and enforcing them in case of assaults & 33 & 18.3 \\
\hline Determine visit hours and number of visitors and nurses not interfering in visits & 21 & 11.7 \\
\hline Providing equipment and resources at the hospital & 34 & 18.9 \\
\hline Spreading awareness among relatives of patients & 5 & 2.8 \\
\hline Physicians available at their places 24 hours & 20 & 11.1 \\
\hline Continuous training for nurses & 8 & 4.4 \\
\hline
\end{tabular}

\# not mutually response

Table (2): shows that the majority $(89.4 \%)$ of staff nurses suggest that the availability of enough security personnel in each department is adequate for the handling of WPV, while 18.9\% suggest providing equipment and resources at the hospital and $18.3 \%$ suggested putting laws and enforcing them in case of assaults.

Table (3) distribution regarding workplace violence reporting among the studied staff nurses (no. $=180)$.

\begin{tabular}{|c|c|c|c|c|}
\hline \multirow[t]{2}{*}{ Items } & \multicolumn{2}{|c|}{ Yes } & \multicolumn{2}{|c|}{ No } \\
\hline & no. & $\%$ & no. & $\%$ \\
\hline $\begin{array}{l}\text { Instructed to report physical or verbal abuse regardless of the level } \\
\text { of severity or harm }\end{array}$ & 95 & 52.8 & 85 & 47.2 \\
\hline \multicolumn{5}{|l|}{ Forms of reporting WPV } \\
\hline Inform director manager & 123 & 68.3 & 57 & 31.7 \\
\hline Alert person to stop the workplace violence & 22 & 12.2 & 158 & 87.8 \\
\hline Ignore the situation & 17 & 9.4 & 163 & 90.6 \\
\hline Change the department & 10 & 5.6 & 170 & 94.4 \\
\hline Informed security, & 113 & 62.8 & 67 & 37.2 \\
\hline informed the charge nurse & 29 & 16.1 & 151 & 83.9 \\
\hline \multicolumn{5}{|l|}{ Responsibility of WPV } \\
\hline Colleagues & 16 & 8.9 & 164 & 91.1 \\
\hline Charge nurse & 25 & 13.9 & 155 & 86.1 \\
\hline Nurse manager & 13 & 7.2 & 167 & 92.8 \\
\hline Physician & 31 & 17.2 & 149 & 82.8 \\
\hline Administrative colleges & 16 & 8.9 & 164 & 91.1 \\
\hline Patients & 125 & 69.4 & 55 & 30.6 \\
\hline Relatives & 166 & 92.2 & 14 & 7.8 \\
\hline
\end{tabular}

Table (3) clarifies that more than half $(52.2 \%)$ of staff nurses have been instructed to report physical or verbal abuse regardless of the level of severity or harm. Also, 68.3\% reported WPV by informing the director manager, while $62.8 \%$ informed security. Also, 69.4\% perceive patients as responsible for WPV, 92.2\% perceive relatives as responsible for WPV, and only $7.2 \%$ perceive nurse managers as responsible for WPV. 
Minia Scientific Nursing Journal (Print - ISSN 2537-012X) (Online - ISSN 2785-9797) Vol. (10) No. (1) December 2021

Table (4) distribution regarding the effect of workplace violence on absenteeism among the studied staff nurses (no. $=180)$.

\begin{tabular}{|c|c|c|c|c|}
\hline \multicolumn{1}{|c|}{ Items } & \multicolumn{2}{|c|}{ Yes } & \multicolumn{2}{c|}{ No } \\
\cline { 2 - 5 } & no. & \% & no. & \% \\
\hline 1.Workplace violence can lead to absenteeism & 140 & 77.8 & 40 & 22.2 \\
\hline 1. The main causes of absenteeism are workplace violence & 117 & 65.0 & 63 & 35.0 \\
\hline 2. The most common form of workplace violence that cause absenteeism from & 25 & 13.9 & 155 & 86.1 \\
\hline a. Colleagues & 71 & 39.4 & 109 & 60.6 \\
\hline b. Charge nurse & 11 & 6.1 & 169 & 93.9 \\
\hline c. Nurse manager & 65 & 36.1 & 115 & 63.9 \\
\hline d. Physician & 18 & 10.0 & 162 & 90.0 \\
\hline e. Administrative colleges & 120 & 66.7 & 60 & 33.3 \\
\hline f. Patients & 159 & 88.3 & 21 & 11.7 \\
\hline g. Relatives & 113 & 62.8 & 67 & 37.2 \\
\hline In your opinion, workplace violence can lead to retirement & $\mathbf{1 8 0}$ & $\mathbf{1 0 0 . 0}$ \\
\hline
\end{tabular}

Table (4) shows that $77.8 \%$ of staff nurses agree that WPV can lead to absenteeism, while $65 \%$ agree that the main cause is WPV. Moreover, the most common form of WPV that causes absenteeism is relatives with (88.3\%) followed by patients with $(66.7 \%)$. Also, $62.8 \%$ of staff nurses agreed that WPV could lead to retirement.

Table (5): Correlation between WPV and absenteeism among the studied staff nurses

\begin{tabular}{|l|c|c|c|c|}
\hline Variables & \multicolumn{2}{|c|}{ WPV } & \multicolumn{2}{|c|}{ Absenteeism } \\
\cline { 2 - 5 } & $\mathbf{r}$ & $\mathbf{p}$ & $\mathbf{r}$ & $\mathbf{P}$ \\
\hline WPV & 1 & & & \\
\hline Absenteeism & 0.22 & $.002 * *$ & 1 & \\
\hline
\end{tabular}

Table (5) there is positive weak correlation between WPV among them and their absenteeism $(r=0.22, \mathrm{P}=0.002)$

Table (6) mean and standard deviation of workplace violence with demographic characteristics of the studied staff nurses $(\mathbf{n}=\mathbf{1 8 0})$.

\begin{tabular}{|c|c|c|c|c|}
\hline \multirow{2}{*}{ Variables } & \multicolumn{2}{|c|}{ WPV } & \multirow{2}{*}{ ANOVA test } & \multirow[t]{2}{*}{ P-value } \\
\hline & Mean & SD & & \\
\hline \multicolumn{5}{|l|}{ Age (years) } \\
\hline $20-29$ & 41.94 & 11.26 & \multirow[t]{4}{*}{3.67} & \multirow[t]{4}{*}{$0.01 *$} \\
\hline $30-39$ & 41.92 & 12.00 & & \\
\hline $40-49$ & 38.38 & 11.10 & & \\
\hline $50-59$ & 35.03 & 11.88 & & \\
\hline \multicolumn{5}{|l|}{ Gender } \\
\hline Male & 42.97 & 9.97 & \multirow[t]{2}{*}{7.55} & \multirow[t]{2}{*}{$0.007^{* *}$} \\
\hline Female & 36.76 & 11.91 & & \\
\hline \multicolumn{5}{|l|}{ Residence } \\
\hline Rural & 36.83 & 11.83 & \multirow[t]{2}{*}{3.04} & \multirow[t]{2}{*}{0.08} \\
\hline Urban & 40.13 & 11.53 & & \\
\hline \multicolumn{5}{|l|}{ Marital status } \\
\hline Single & 34.44 & 12.06 & \multirow[t]{4}{*}{1.42} & \multirow[t]{4}{*}{0.23} \\
\hline Married & 38.42 & 12.17 & & \\
\hline Divorced & 40.00 & 9.84 & & \\
\hline Widow & 40.71 & 3.74 & & \\
\hline \multicolumn{5}{|l|}{ Nursing qualification } \\
\hline Bachelor & 31.67 & 12.17 & \multirow[t]{3}{*}{1.81} & \multirow[t]{3}{*}{0.16} \\
\hline Technical institute & 38.50 & 12.03 & & \\
\hline Diploma & 38.08 & 11.36 & & \\
\hline \multicolumn{5}{|l|}{ Current position } \\
\hline Nurse & 38.43 & 11.61 & \multirow[t]{5}{*}{1.79} & \multirow[t]{5}{*}{0.13} \\
\hline Unit supervisor & 33.75 & 22.98 & & \\
\hline Educator & 17.50 & 0.00 & & \\
\hline Nurse specialist & 30.56 & 11.44 & & \\
\hline Assistant nurse manager & 37.50 & 0.00 & & \\
\hline
\end{tabular}

Table (6) demonstrates that there is a significant relation between age, gender of staff nurses, and WPV $(\mathrm{P}=0.01$, 0.007 respectively). The highest percent of WPV (41.9\%) are in the age group $20-29,(42.9 \%)$ for males but the lowest percent of WPV (35\%) are in the age group $50-59$, and (36.7\%) for females.

Table (7) mean and standard deviation of absenteeism with personal characteristics of the studied staff nurses (no. $=180)$.

\begin{tabular}{|c|c|c|c|c|}
\hline \multirow[t]{2}{*}{ Variables } & \multicolumn{2}{|c|}{ Absenteeism } & \multirow[t]{2}{*}{ ANOVA test } & \multirow[t]{2}{*}{ p-value } \\
\hline & Mean & SD & & \\
\hline \multicolumn{5}{|l|}{ Age (years) } \\
\hline $20-29$ & 67.50 & 37.87 & \multirow[t]{4}{*}{.19} & \multirow[t]{4}{*}{0.89} \\
\hline $30-39$ & 71.24 & 36.53 & & \\
\hline $40-49$ & 65.74 & 41.01 & & \\
\hline $50-59$ & 71.79 & 42.70 & & \\
\hline \multicolumn{5}{|l|}{ Gender } \\
\hline Male & 67.71 & 38.32 & .01 & 0.89 \\
\hline
\end{tabular}




\begin{tabular}{|c|c|c|c|c|}
\hline \multirow[t]{2}{*}{ Variables } & \multicolumn{2}{|c|}{ Absenteeism } & \multirow[t]{3}{*}{ ANOVA test } & \multirow[t]{3}{*}{ p-value } \\
\hline & Mean & SD & & \\
\hline Female & 68.69 & 38.34 & & \\
\hline \multicolumn{5}{|l|}{ Residence } \\
\hline Rural & 68.82 & 37.48 & \multirow[t]{2}{*}{.02} & \multirow[t]{2}{*}{0.87} \\
\hline Urban & 67.86 & 40.18 & & \\
\hline \multicolumn{5}{|l|}{ Marital status } \\
\hline Single & 72.22 & 38.63 & \multirow[t]{4}{*}{.34} & \multirow[t]{4}{*}{0.79} \\
\hline Married & 66.67 & 38.17 & & \\
\hline Divorced & 74.51 & 40.02 & & \\
\hline Widow & 66.67 & 38.49 & & \\
\hline \multicolumn{5}{|l|}{ Nursing qualification } \\
\hline Bachelor & 94.44 & 12.97 & \multirow[t]{3}{*}{6.25} & \multirow[t]{3}{*}{$0.002 *$} \\
\hline Technical institute & 73.33 & 37.13 & & \\
\hline Diploma & 58.97 & 39.45 & & \\
\hline \multicolumn{5}{|l|}{ Current position } \\
\hline Nurse & 67.07 & 38.55 & \multirow[t]{5}{*}{1.42} & \multirow[t]{5}{*}{0.22} \\
\hline Unit supervisor & 50.00 & 70.71 & & \\
\hline Educator & 100.00 & 0.00 & & \\
\hline Nurse specialist & 92.59 & 14.70 & & \\
\hline Assistant nurse manager & 100.00 & 0.00 & & \\
\hline \multicolumn{5}{|l|}{ Years of experience } \\
\hline Under 5 years & 66.67 & 39.57 & \multirow[t]{3}{*}{0.07} & \multirow[t]{3}{*}{0.92} \\
\hline $5-10$ years & 68.47 & 38.45 & & \\
\hline More than ten years & 69.39 & 37.89 & & \\
\hline
\end{tabular}

* Significant at $\mathrm{P}$ - value $<0.05$

Table (7) demonstrates that there is no significant relation between personal characteristics of staff nurses and their absenteeism except with nursing qualification $(\mathrm{P}=0.002)$. The highest percent of absenteeism $(94.4 \%)$ are with Bachelor degree while the lowest percent (58.9\%) are diploma nursing.

\section{Discussion:}

Workplace violence is violent or abusive are prevalent in hospitals, with nurses being particularly vulnerable to abuse (Nelson, 2014). Violence in healthcare organizations is an issue that is unique to Egypt, but it is also a significant concern across the globe. In order to do their jobs effectively, nurses must have close contact with patients and their families while working in a complicated environment that may expose them to physical violence. The majority of nurses have been exposed to various types of WPV from patients and/or their families and aggressive conduct from their colleagues, management, and/or other patients. There have been reports of verbal threats, physical and/or sexual attacks on medical workers by patients and/or their families who have interacted with the medical staff (Kaya et al., 2016). Any of these behaviors of WPV have a detrimental effect on the safety and health of nurses, and they have the potential to impair the quality of patient care (Ma et al., 2021). So this study aims to assess nurses' perception of workplace violence and its relation to their absenteeism.

Regarding personal characteristics of staff nurses (Table 1), nearly half of staff nurses were in the age group 2029 with mean \pm SD $33.5 \pm 9.6$ years, the majority of staff nurses were females, and more than two-thirds lived in a rural area. This might be due to the majority of a nursing career is feminine.

These findings consistency with an Egyptian study performed by Kabbash and El-Sallamy, (2019), identified the prevalence of workplace violence at Tanta University Emergency Hospital and its impact on affected workers, showed that half of the studied health care workers aged between $20-<30$ years with mean age $31.2 \pm 7.95$ years.

Also, Hassan et al., (2020) assessed the prevalence of external and internal violence against staff nurses and studied the violence-associated factors such as perpetrators, the attitude of staff nurses following aggression incidents, consequences, and impact on staff nurses and work in Minia district showed that the majority of the studied sample was female staff nurses and nearly to two-thirds of their lives in the rural area.

Moreover, El Sharakawy and Mondoor, (2021) determined the prevalence, pattern, associated factors, and impacts of WPV among female Healthcare workers at AlZahraa University Hospital and detected the causes and sought out suggestions to prevent such incidents showed that The age of the studied HCWs ranged from 20 to 49 years with mean and SD $29.0+6.1$

Regarding the marital status of the studied nurses, two-thirds of them were married, and nearly to half of them had a nursing diploma. Concerning the experience years, more than half $(54.4 \%)$ of staff nurses had $>10$ years of experience, and all $(100.0 \%)$ of the studied staff nurses have never received training in preventing and mitigating the hospital WPV.

This finding is consistent with an Egyptian study done by Saboula et al., (2018) determined pattern, prevalence, and risk factors of workplace violence among staff nurses in outpatient clinics of Menoufia Governorate Hospitals mentioned that most of staff nurses (95\%) working as staff nurse didn't receive educational sessions about violence in the health care setting and only $3.5 \%$ of studied staff nurses attended sessions about WPV.

Also, Maghraby et al., (2020) assessed the magnitude of sexual harassment, its' effect on nurses and to identify the predictors of workplace sexual harassment in Sohag University Hospital, one of the university hospitals of Upper Egypt represented that no educational sessions about workplace sexual harassment were provided.

Moreover, A recent Egyptian study performed by Hassan et al., (2020) mentioned that approximately $50 \%$ of the staff nurses were married, and Gabr et al., (2021) evaluated the prevalence of WPV against Egyptian female nurses and to determine its sociodemographic, and occupational risk factors presented that half of the studied participated their experience in nursing was more than 15 years. 
Regarding workplace violence among staff nurses (figure 1), the majority of staff nurses have been exposed to WPV, and a minority of them have not been exposed to workplace violence.

This result is similar to what found in previous studies done in Egypt in different places as Anwar et al., (2016) assessed the magnitude and patterns of violence against HCWs in Beni-Suef Governmental hospitals, exploring the reporting, consequences, and impact of these aggression incidents on daily health service performance mentioned that the majority of the studied staff nurses were exposed to workplace violence. Saboula et al., (2018) revealed that more than three quarters $(79.0 \%)$ of studied staff nurses were exposed to various types of violence through their work in outpatient clinics.

Also, Kabbash and El-Sallamy, (2019) showed that more than three-quarters of the nurses exposed to verbal violence, followed by one-third of them exposed to physical violence and the minority of them exposed to sexual violence; in addition, a recent Egyptian study done by El Sharakawy and Mondoor, (2021), mentioned that nearly to three-quarters of the studied nurses were exposed to violence and Gabr et al., (2021) showed that the prevalence of WPV was estimated to affect nearly to three-quarters of the studied nurses. These different percentages are related to different study settings, sample sizes, cultural and socio-economic differences between the countries.

Regarding suggestions of the studied staff nurses for workplace violence handling (Table, 2), the majority of the studied staff nurses mentioned that availability of enough security personnel in each department, providing equipment and resources at the hospital, putting laws and enforcing them in case of assaults, determine visit hours and the number of visitors and staff nurses not interfering in visits and availability physicians at their places 24 hours were the most common suggestion to reduce workplace violence.

El Sharkawy and Mondoor, (2021) presented that provision of adequate equipment and medicine, low socioeconomic status of patients, legislation, strengthened security measures, restricted public access to examination rooms, unavailability of medical equipment and treatment, and inadequate security were suggested as preventive measures for violence.

Regarding reporting workplace violence among the studied staff nurses (Table, 3), more than half of staff nurses have been instructed to report physical or verbal abuse regardless of the severity of harm to the direct manager and security. These differences in the subsequent studies reflect different preventive and control strategies in each country and nurses' actions toward reporting workplace violence.

Anwar et al., (2016) showed that more than half of the studied staff nurses reported internal and external workplace violence to direct managers and security and Hassan et al., (2020) presented that more than two-thirds of the studied sample incidents to the administration.

Concerning the person responsible for workplace violence (Table 3), most of the patients relative the main responsible for it followed by more than two-thirds of them were patients themselves, and the minority was the physician and charge nurses. In Egypt, patient relatives are often present inside the hospital throughout the patient's evaluation, investigation, and treatment, despite being against the law.
This result, in the same line with Abdellah and Salama (2017), represented that the patient relatives were responsible for most of the verbal and physical abuses and Saboula et al., (2018) mentioned that the main sources of WPV were patients and patient relatives and the less frequency source of violence was supervision members and the health care members.

Also, Hassan et al., (2020) mentioned that more than half of the studied sample reported that supervisors, colleagues, and administrative staff were the reported perpetrators who committed internal violence against nurses

Regarding workplace violence on absenteeism among the studied staff nurses (Table, 4), the current result reported that more than three-quarters of the studied staff nurses said workplace violence can lead to absenteeism and more than half of them are sure that workplace violence can lead to retirement.

This result is in the same line with Saboula et al. , (2018) showed that $11.5 \%$ of the studied staff nurses reported workplace violence lead to absence from work, and Kabbash and El-Sallamy (2019), who mentioned that more than threequarters of the studied staff nurses don't want to go to work and take vacations.

According to well-established evidence, HCWs subjected to WPV suffer from physical and mental wellbeing impairment and several other negative consequences that end with extended periods of absenteeism, work inefficiency, deterioration of work performance, and high turnover (Cheung and Yip, 2017; Sharma et al. , 2019).

Concerning correlation between WPV, absenteeism, age and experience of staff nurses (Table, 5) the current finding showed that negative weak correlation between WPV among the studied sample with age, and their experience $(\mathrm{r}=$ $0.19, \mathrm{P}=0.007 \& \mathrm{r}=-0.17, \mathrm{P}=0.01$ respectively). But, there is positive weak correlation between WPV among them and their absenteeism $(\mathrm{r}=0.22, \mathrm{P}=0.002)$ and positive moderate correlation between the studied sample age and their years of experience $(\mathrm{r}=0.72, \mathrm{P}=0.0001)$. This can be explained by the fact that older and more experienced HCWs are better at predicting, evaluating, managing, and judging hazardous situations than younger and less experienced HCWs because they are more professional and mature enough to deal with social events and emergencies have sufficient communication skills.

Abd El Hamid et al., (2017) assessed the impact of workplace violence on job satisfaction among psychiatric nursing staff from the inpatient departments and outpatient clinic of EL-Abbassia Mental Health Hospital in Cairo, there were statistically significant relation between violence and age, but they differ in the point of there are no statistically significant relations between levels of experience, might due to their studied sample their experience years was newly ranged between $<$ one year to more than three years

Ghareeb et al., (2021) showed that there were statistically significant associations between duration of work ( $\leq 10$ years), and history of exposure to WPV during the last six months $(\mathrm{P}<0.05)$

Concerning the mean and standard deviation of workplace violence with personal characteristics of the studied staff nurses (Table, 6), there is a significant relation between the gender of staff nurses and WPV. The highest mean of WPV was for males, but the lowest mean of WPV was for females. $(P=0.007)$ 
In the same line, Abdellah and Salama (2017), this current result showed that males had higher percent of physical attacks than female nurses and Saboula et al., (2018) found no statistically significant relation between WPV and marital status, work experience. On the other hand, nurses aged 50 years or more were likely to be more exposed to WPV $(\mathrm{P}=0.015)$

In addition, Ghareeb et al., (2021) presented statistically significant associations between gender (males) and history of exposure to WPV.

On the opposite side, a study done by Abdellah and Salama, (2017) mentioned that the higher prevalence in the younger age group can be attributed to a lower threshold for insult and pain and less maturity compared to the older age group. Also, El Sharkawy and Mondoor (2021) reported no significant association between workplace violence with age and duration of employment.

Conclusion: The findings of this study revealed that the majority of staff nurses have been exposed to WPV, and a minority of them have not been exposed to workplace violence. More than half of staff nurses have been instructed to report physical or verbal abuse regardless of the severity or harm to the direct manager and security. Most of the patients relative is the main responsible source for it followed by more than two-thirds of them were patients themselves, and the minority was the physician and charge staff nurses and more than three-quarters of the studie staff $d$ nurses said workplace violence can lead to absenteeism and more than half of them are sure that workplace violence can lead to retirement. In addition, there is a positive weak correlation between workplace violence among the studied staff nurses and their absenteeism.

\section{Recommendations}

- Encourage nursing staff to do the incident reports.

- Periodical in-service training programs should be designed and done about how nursing staff managing violent behaviors.

- Safety training programs for the prevention of violence and to help staff nurses to understand violence-related reasons and risk factors, warning signs, procedures for its avoidance, prevention, and management

- Develop a management strategy to overcome WPV against HCWs.

- A protocol for staff nurses should be developed to promote the staff's awareness of aggressive behavior.

- Policies and legislation targeting violent acts should be instituted and developed, and a high percentage of staff nurses need training in violence management.

- A workplace violence policy should be developed to explain the process after an employee has been assaulted. This policy should include how to report the incidence, reasons for non-reporting of incidents, and follow-up to reports of incidents.

- Patients, their relatives, and visitors should be aware of their bill of rights and respect their healthcare facilities' responsibilities.

\section{References}

(1) Abd El hamid, M., Saeed Abd El mohsen, N., \& Abd. El Halim Osman, Z. (2017). Reletionship between Workplace Violence and Job Satisfaction among Nurses Working In Psychitric Setting. Egyptian Journal of Health Care, 8(2), 256-269.

$P$ a g e | 53
(2) Abdellah, R. F., \& Salama, K. M. (2017). Prevalence and risk factors of workplace violence against health care workers in emergency department in Ismailia, Egypt. Pan African medical journal, 26(1), 1-8.

(3) Abdel-Salam, D. (2014). Violence against physicians working in emergency departments in Assiut, Egypt. Journal of High Institute of Public Health, 44(2), 98-107.

(4) Cheung T, \& Yip P (2017). Workplace violence towards nurses in Hong Kong: prevalence and correlates. BMC Public Health 17(1):196.

(5) El Sharkawy SA, \& Mondoor WR, (2021). Violence among Female Health Care Workers. Egyptian Journal of Occupational Medicine, 45(3), 199-216.

(6) El-Houfey, A. A., El-Maged, N. S. A., Elserogy, Y. M., \& El Ansari, W. (2015). Workplace bullying against medical and nursing team working at emergency departments in Assiut University Hospital. IOSR Journal of Nursing and Health Science, 4(2), 1-9.

(7) Emergency Nurses Association. (2010). Workplace Violence Staff Assessment Survey. Retrieved from https://www.ena.org/practice-research/Practice/ ViolenceToolKit/Documents/toolkitpg5.htm.

(8) Gabr, H. M., Younis, F. E., \& El-Badry, A. S. (2021). Workplace Violence against Female Nurses in Menoufia Governorate, Egypt: an Epidemiological Study. The Egyptian Family Medicine Journal, 5(1), 17-27.

(9) Ghareeb, N. S., El-Shafei, D. A., \& Eladl, A. M. (2021). Workplace violence among healthcare workers during COVID-19 pandemic in a Jordanian governmental hospital: the tip of the iceberg. Environmental Science and Pollution Research, 1-9.

(10) Gillespie, G. L., Pekar, B., Byczkowski, T. L., \& Fisher, B. S. (2017). Worker, workplace, and community/environmental risk factors for workplace violence in emergency departments. Archives of environmental \& occupational health, 72(2), 79-86.

(11) Granstra, K. (2015). Nurse against nurse: Horizontal bullying in the nursing profession. Journal of Healthcare Management, 60(4), 249-257. Retrieved from http://www.ncbi.nlm.nih.gov/pubmed/26364348.

(12) Hassan, E. E., Amein, N. M., \& Ahmed, S. M. (2020). Workplace violence against nurses at Minia district hospitals. Journal of Health Sciences, 10(1), 76-82.

(13) Hutchinson, M., Jackson, D., Haigh, C., \& Hayter, M. (2013). Editorial: Five years of scholarship on violence, bullying and aggression towards nurses in the workplace: What have we learned? Journal of Clinical Nursing, 22(78), 903-905. doi: 10.1111/jocn. 12139.

(14) Itzhaki, M., Peles-Bortz, A., Kostistky, H., Barnoy, D., Filshtinsky, V., \& Bluvstein, I. (2015). Exposure of mental health nurses to violence associated with job stress, life satisfaction, staff resilience, and post-traumatic growth. International Journal of Mental Health Nursing, 24(5), 403412. doi: 10.1111/inm.12151.

(15) Kabbash, I. A., \& El-Sallamy, R. (2019). Violence against health care workers in emergency hospital, Tanta University, Egypt. Egyptian Journal of Occupational Medicine, 43(2), 215-228.

(16) Kaya S, Demir IB, Karsavuran S, Ürek D, Ilgün G. (2016). Violence against doctors and nurses in Hospitals in Turkey. J Forensic Nurs. 2016;12(1):26-34.

(17) Ma, J., Chen, X., Zheng, Q., Zhang, Y., Ming, Z., Wang, D., ... \& Li, X. (2021). Serious workplace violence against healthcare providers in China between 2004 and 2018. Frontiers in public health, 8, 963.

(18) Maghraby, R. A., Elgibaly, O., \& El-Gazzar, A. F. (2020). Workplace sexual harassment among nurses of a university hospital in Egypt. Sexual \& Reproductive Healthcare, 25, 100519.

Warda H., et al 
(19) Nelson R. (2014). Tackling violence against healthcare workers. The Lancet. p. 1373-4.

(20) Norris, T. (2018). Workplace Violence Among Nurses and Nursing Assistants in Texas.

(21) OSHA. (2016). Workplace Violence. Retrieved from https://www.osha.gov/SLTC/workplaceviolence/

(22) Park, M., Cho, S. H., \& Hong, H. J. (2015). Prevalence and perpetrators of workplace violence by nursing unit and the relationship between violence and the perceived work environment. Journal of nursing scholarship, 47(1), 87-95.

(23) Pich, J., Hazelton, M., Sundin, D., \& Kable, A. (2011). Patient-related violence at triage: A qualitative descriptive study. International Emergency Nursing, 19(1), 12-19. doi: 10.1016/j.ienj.2009.11.007.

(24) Purpora, C., \& Blegen, M. A. (2015). Job satisfaction and horizontal violence in hospital staff registered nurses: The mediating role of peer relationships. Journal of Clinical Nursing, 24(15-16), 2286-2294. doi: 10.1111/jocn. 12818.

(25) Queens and Health. (2016). Occupational Violence Prevention in Queensland Health's Hospital and Health Services. from www.health.qld.gov.au

(26) Rosen, J. (2013). Overview and summary: Patient and visitor violence: What do we know? What can we do?
Online Journal of Issues in Nursing, 18(1), 1-1. doi: 10.3912/OJIN.Vol18No01ManOS.

(27) Saboula, N. E., Abd El-Aal, B. G., \& Shalaby, A. H. (2018). Prevalence, Patterns, and Risk Factors of Workplace Violence among Nurses in Outpatient Clinics of Menoufia Governorate Hospitals. International Journal of Novel Research in Healthcare and Nursing; 5 (1): 53- 67.

(28) Sharma S, Lal Gautam P, Sharma S, Kaur A, Bhatia N, Singh G, Kaur P, Kumar A (2019). Questionnaire-based evaluation of factors leading to patient-physician distrust and violence against healthcare workers. Indian journal of critical care medicine : peer-reviewed, official publication of Indian Society of Critical Care Medicine 23(7):302-309.

(29) Singh, R., Van der Colff J., \& Stellenberg E. (2012). Factors contributing to absenteeism of nurses in primary care centres in the ethekwini municipal district of kwazulunatal, published master degree in the Faculty of Health Sciences at Stellenbosch University.

(30) Zhang, L., Wang, A., Xie, X., Zhou, Y., Li, J., Yang, L., Zhang, J. (2017). Workplace violence against nurses: A cross sectional study. International Journal of Nursing Studies, 72, 8-14. 